\title{
SISTEM PENJADWALAN UJIAN DOKTOR PADA PASCASARJANA UNIVERSITAS DIPONEGORO
}

\author{
Rizka Ella Setyani, Sukmawati Nur Endah \\ Jurusan Ilmu Komputer/ Informatika, Universitas Diponegoro \\ Email : rizka.ella@gmail.com, sukmane@undip.ac.id
}

\begin{abstract}
ABSTRAK
Pascasarjana Universitas Diponegoro terus melakukan pembangunan baik secara fisik maupun dalam segi sistem informasi mengikuti semakin canggihnya teknologi untuk menjawab berbagai tantangan yang ada. Salah satu dari usaha pembangunan dalam segi sistem informasi tersebut adalah dengan pembuatan pengelolaan data yang berhubungan dengan pelaksanaan ujian doktor. Pengelolaan data yang semula dilakukan secara manual sehingga kurang terorganisir kini dapat dilakukan dengan lebih mudah dan efisien. Penelitian ini membahas mengenai Sistem Penjadwalan Ujian Doktor yang dalam pengembangannya menggunakan metode waterfall dan merupakan sistem berbasis web. Sistem ini dibangun menggunakan bahasa pemograman PHP dan basis data MySQL untuk memudahkan kinerja administrator yang bertugas membuat jadwal dan mengelola data mahasiswa yang akan melakukan ujian doktor agar tidak terjadi jadwal yang bertabrakan sehingga dapat lebih terstruktur, dapat menambah keakuratan data, dan mempercepat pemrosesan data yang ada. Bagi mahasiswa pascasarjana sistem ini mempermudah dalam mengetahui jadwal ujian, statistik ujian doktor, serta informasi yang berkaitan dengan pelaksanaan ujian doktor karena dapat diakses secara online. Implementasi dari sistem ini dapat disinkronkan dengan sistem yang sudah ada sebelumnya dan dapat berjalan dengan baik.
\end{abstract}

Kata kunci : sistem penjadwalan, sistem penjadwalan ujian, PHP

\section{PENDAHULUAN}

Kemajuan ilmu pengetahuan dan teknologi saat ini sangat pesat dan telah memberikan banyak kemudahan untuk melakukan berbagai kegiatan sehari - hari. Pekerjaan yang semula dilakukan secara manual, membutuhkan waktu yang lama dan merepotkan, sekarang dapat dilakukan secara lebih mudah, efektif dan efisien dengan menggunakan teknologi yang semakin canggih.

Pascasarjana Universitas Diponegoro merupakan badan pendidikan yang mempersiapkan lulusan yang cakap dan berkompeten dibidangnya. Saat ini, Pascasarjana Universitas Diponegoro masih menggunakan cara manual dalam pengelolaan penjadwalan ujian doktor. Hal tersebut menyebabkan kemungkinan terjadinya jadwal yang bertabrakan, kurang transparansi dengan mahasiswa, dan kurang terorganisir antar orangorang yang terlibat dalam pengujian tersebut.

Penelitian yang telah dilakukan adalah membuat Sistem Penjadwalan Ujian Doktor pada Pascasarjana Universitas Diponegoro. Sistem penjadwalan ini dibangun untuk membantu Pascasarjana Universitas Diponegoro dalam mengelola data mahasiswa yang akan melakukan ujian doktor agar tidak terjadi jadwal yang bertabrakan sehingga memudahkan mahasiswa pascasarjana dalam mengetahui jadwal ujian, statistik ujian doktor, serta informasi yang berkaitan dengan pelaksanaan ujian doktor.

Tujuan dari penelitian ini adalah membantu Pascasarjana Universitas Diponegoro dalam mengatur jadwal ujian doktor serta orang-orang yang terlibat di dalamnya dan memudahkan mahasiswa pascasarjana dalam mendapatkan informasi tentang jadwal ujian doktor sehingga penjadwalan ujian doktor dapat dilakukan dengan cepat, mudah, dan lebih efisien. Sistem Penjadwalan Ujian Doktor pada Pascasarjana Universitas Diponegoro dibangun menggunakan bahasa pemrograman PHP dan database MySQL [2]. 


\section{DESKRIPSI UMUM}

Sistem Penjadwalan Ujian Doktor pada Pascasarjana Universitas Diponegoro merupakan sistem yang digunakan untuk mengolah data mahasiswa yang diusulkan untuk melakukan ujian doktor, data penguji, data program studi, pembuatan jadwal ujian, data berita, data user, manajemen video sidang, dan statistik ujian doktor.

\section{I.Karakteristik pengguna Sistem Penjadwalan Ujian Doktor yaitu :}

1. Administrator Pascasarjana : Pengguna yang bekerja ditingkat pascasarjana.

Hak akses :

a) Mengelola data jadwal

b) Melihat jadwal ujian doktor

c) Mengelola data prodi

d) Mengelola berita

e) Mengelola data user

f) Upload dan hapus video sidang

g) Melihat statistik ujian doktor.

2. Administrator Program Studi : Pengguna yang bekerja ditingkat program studi.

Hak akses :

a) Mengelola data usulan

b) Mengelola data penguji

c) Melihat jadwal ujian doktor

d) Melihat berita terkini

e) Melihat dan download video sidang

f) Melihat statistik ujian doktor.

3. Guest : Pengguna yang menggunakan sistem tanpa login misalnya mahasiswa, dosen, dan lain-lain.

Hak akses :

a) Melihat jadwal ujian doktor

b) Melihat berita terkini

c) Melihat dan download video sidang

d) Melihat statistik ujian doktor.

\section{Kebutuhan Fungsional}

Kebutuhan fungsional Sistem Penjadwalan Ujian Doktor dapat dilihat pada tabel 1 berikut ini :
Tabel 1. Kebutuhan Fungsional

\begin{tabular}{|c|c|c|}
\hline No & SRS-ID & Deskripsi \\
\hline 1. & SRS-SPUD-F-001 & $\begin{array}{l}\text { Otentikasi dan autorisasi } \\
\text { login }\end{array}$ \\
\hline 2. & SRS-SPUD-F-002 & Menambah data usulan \\
\hline 3. & SRS-SPUD-F-003 & Mengubah data usulan \\
\hline 4. & SRS-SPUD-F-004 & Menghapus data usulan \\
\hline 5. & SRS-SPUD-F-005 & $\begin{array}{l}\text { Menampilkan data } \\
\text { usulan }\end{array}$ \\
\hline 6. & SRS-SPUD-F-006 & $\begin{array}{l}\text { Membuat jadwal ujian } \\
\text { doktor }\end{array}$ \\
\hline 7. & SRS-SPUD-F-007 & $\begin{array}{l}\text { Mengubah jadwal ujian } \\
\text { doktor }\end{array}$ \\
\hline 8. & SRS-SPUD-F-008 & $\begin{array}{l}\text { Menghapus jadwal ujian } \\
\text { doktor }\end{array}$ \\
\hline 9. & SRS-SPUD-F-009 & $\begin{array}{l}\text { Menampilkan jadwal } \\
\text { ujian doktor }\end{array}$ \\
\hline 10. & SRS-SPUD-F-010 & $\begin{array}{l}\text { Menampilkan statistik } \\
\text { ujian doktor }\end{array}$ \\
\hline 11. & SRS-SPUD-F-011 & Menambah data penguji \\
\hline 12. & SRS-SPUD-F-012 & Mengubah data penguji \\
\hline 13. & SRS-SPUD-F-013 & Menghapus data penguji \\
\hline 14. & SRS-SPUD-F-014 & $\begin{array}{l}\text { Menampilkan data } \\
\text { penguji }\end{array}$ \\
\hline 15. & SRS-SPUD-F-015 & Menambah data prodi \\
\hline 16. & SRS-SPUD-F-016 & Mengubah data prodi \\
\hline 17. & SRS-SPUD-F-017 & Menghapus data prodi \\
\hline 18. & SRS-SPUD-F-018 & Menampilkan data prodi \\
\hline 19. & SRS-SPUD-F-019 & Menambah berita \\
\hline 20. & SRS-SPUD-F-020 & Mengubah berita \\
\hline 21. & SRS-SPUD-F-021 & Menghapus berita \\
\hline 22. & SRS-SPUD-F-022 & Menampilkan berita \\
\hline 23. & SRS-SPUD-F-023 & $\begin{array}{l}\text { Mengupload video } \\
\text { sidang }\end{array}$ \\
\hline 24. & SRS-SPUD-F-024 & Mnghapus video sidang \\
\hline 25. & SRS-SPUD-F-025 & $\begin{array}{l}\text { Mendownload video } \\
\text { sidang }\end{array}$ \\
\hline 26. & SRS-SPUD-F-026 & $\begin{array}{l}\text { Menampilkan video } \\
\text { sidang }\end{array}$ \\
\hline 27. & SRS-SPUD-F-027 & Menambah data user \\
\hline 28. & SRS-SPUD-F-028 & Mengubah data user \\
\hline 29. & SRS-SPUD-F-029 & Menghapus data user \\
\hline 30. & SRS-SPUD-F-030 & Menampilkan data user \\
\hline 31. & SRS-SPUD-F-031 & Logout \\
\hline
\end{tabular}

\section{PEMODELAN}

\section{Pemodelan Data}

Data yang diproses dalam Sistem Penjadwalan Ujian Doktor ini meliputi data usulan, data jadwal, data penguji, data user, data prodi, berita dan video. Media yang digunakan untuk mendeskripsikan pemodelan 
data sistem ini adalah ERD (Entity Relationship Diagram). Untuk mengakomodasi kebutuhan data di atas, maka ERD yang dibuat untuk Sistem Penjadwalan Ujian Doktor digambarkan pada gambar 1.
Pada ERD Sistem Penjadwalan Ujian Doktor terdapat 7 buah entitas yang masing-masing entitas memiliki atribut sendiri-sendiri. Terdapat juga 8 buah relasi yang menghubungkan antar entitas.

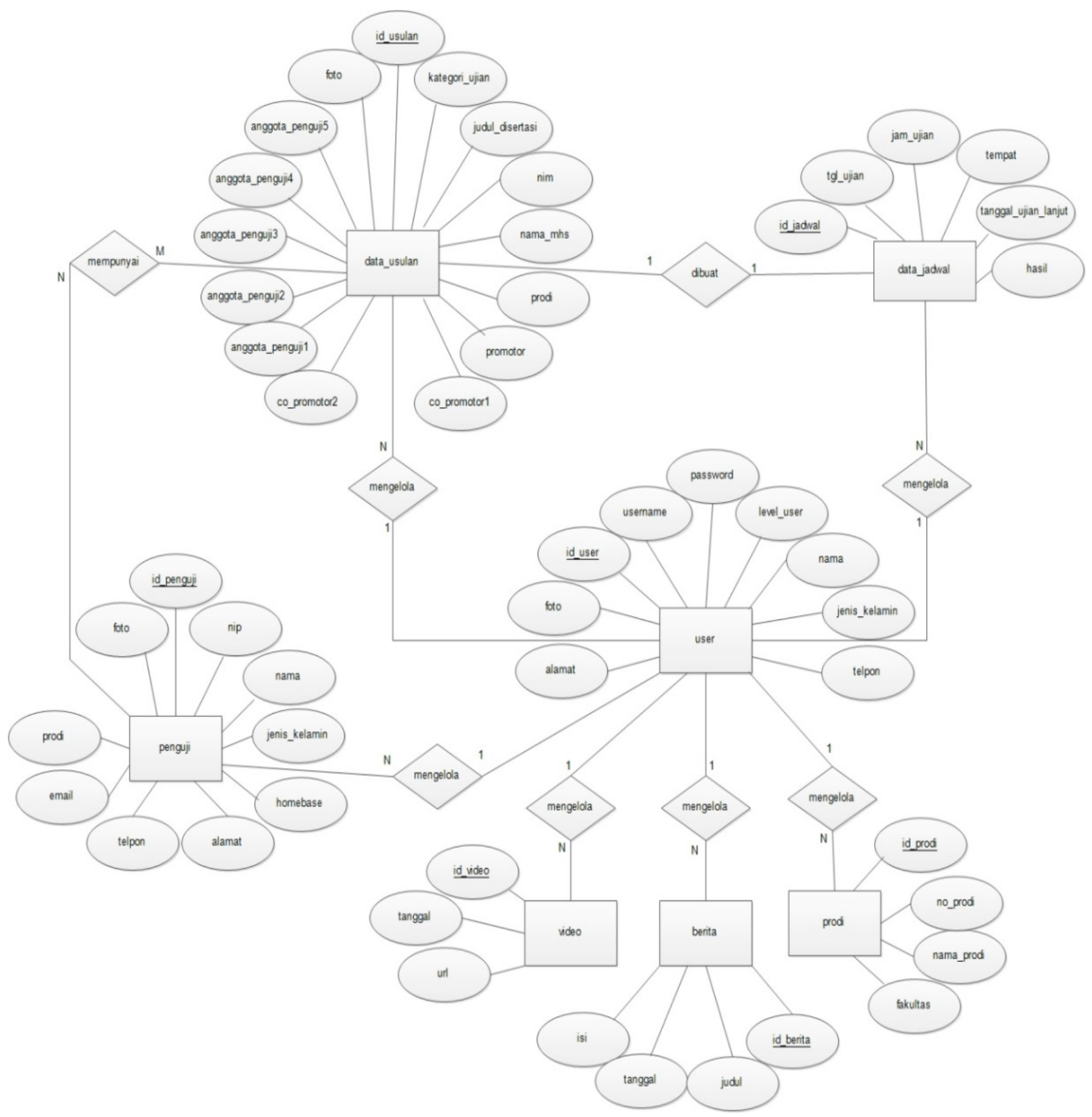

Gambar 1. Entity Relationship Diagram Sistem Penjadwalan Ujian Doktor

\section{Pemodelan Fungsional}

Model fungsional menangkap apakah yang dikerjakan oleh sistem tanpa memperhatikan bagaimana dan kapan dikerjakan. Model fungsional digambarkan dengan diagram alir data. Model yang digunakan untuk mendeskripsikan 
pemodelan fungsional Sistem Penjadwalan Ujian Doktor adalah Context Diagram (CD), Diagram Dekomposisi (DD) dan Data Flow Diagram (DFD) [3] .

\section{Context Diagram (CD)}

Context Diagram dapat juga di katakan sebagai DFD Level-0, karena pada CD hanya mempresentasikan sistem sebagai sebuah blackbox di lingkungan sekitarnya. CD menggambarkan aliran-aliran data ke dalam dan ke luar sistem dan Sistem Penjadwalan Ujian Doktor dapat dilihat pada gambar 2.

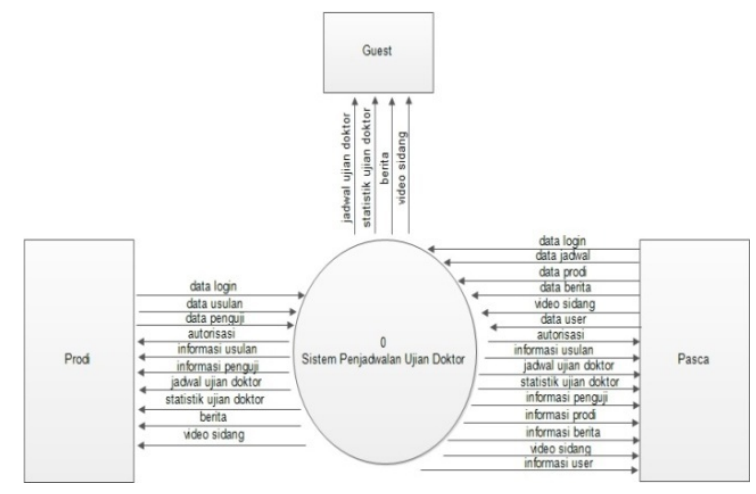

Gambar 2. Context Diagram Sistem Penjadwalan Ujian Doktor

\section{Diagram Dekomposisi (DD)}

Diagram Dekomposisi untuk Sistem Penjadwalan Ujian Doktor dapat dilihat pada gambar 3 sebagai berikut :

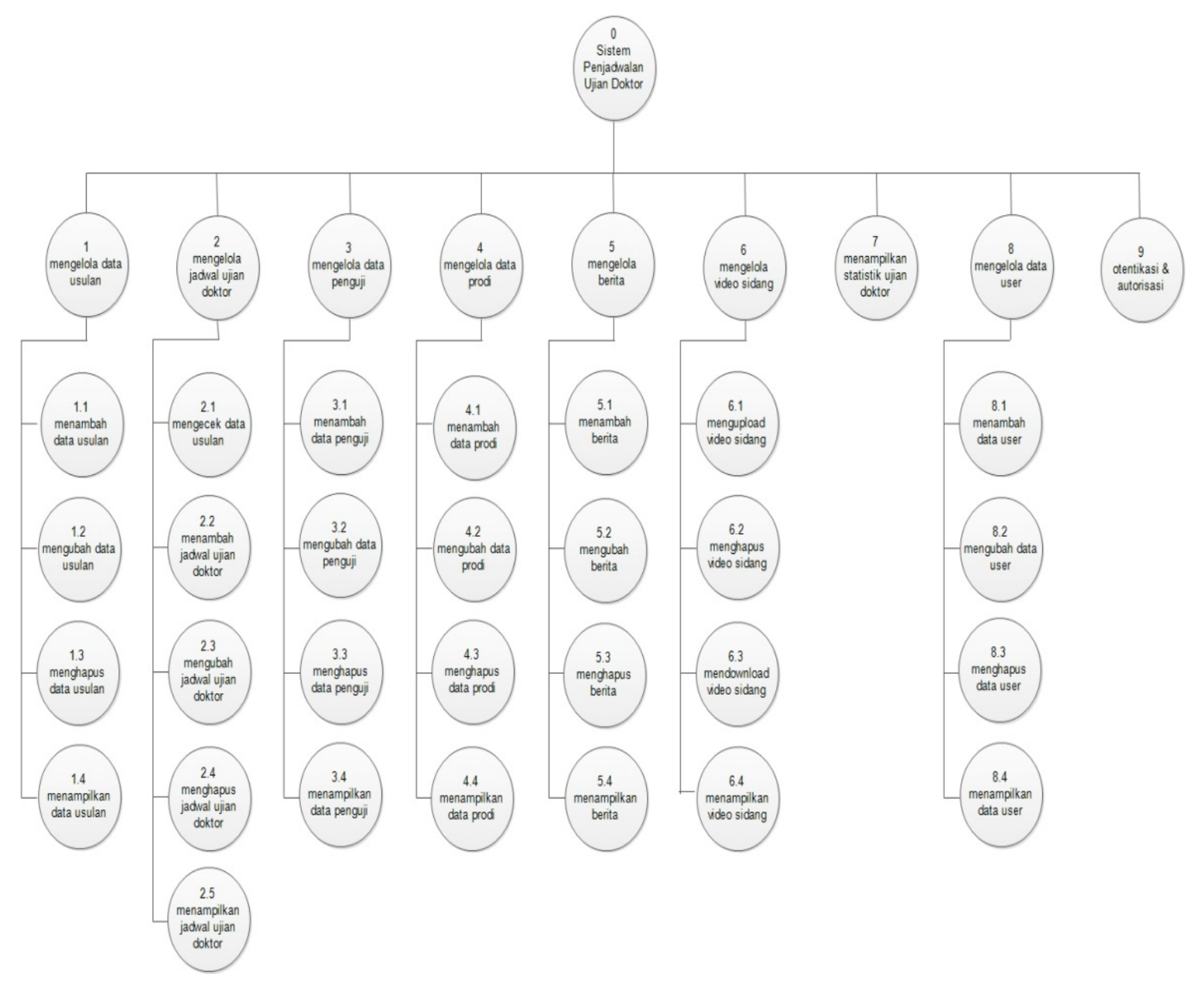

Gambar 3. Diagram Dekomposisi Sistem Penjadwalan Ujian Doktor 


\section{Data Flow Diagram (DFD)}

Data Flow Diagram (DFD) adalah representasi grafik dari sebuah sistem. Data Flow Diagram (DFD) menggambarkan komponen-komponen sebuah sistem, aliranaliran data di mana komponen-komponen tersebut, dan asal, tujuan, dan penyimpanan dari data tersebut [4]. Data Flow Diagram (DFD) merupakan penjabaran lebih lanjut dari
Context Diagram (CD). Data Flow Diagram (DFD) pada Sistem Penjadwalan Ujian Doktor terdapat 2 level yaitu level 1 dan level 2. Untuk penjelasan dari Data Flow Diagram (DFD) level 1 dan level 2 secara detail dapat dilihat pada gambar 4 sampai dengan gambar 11 .

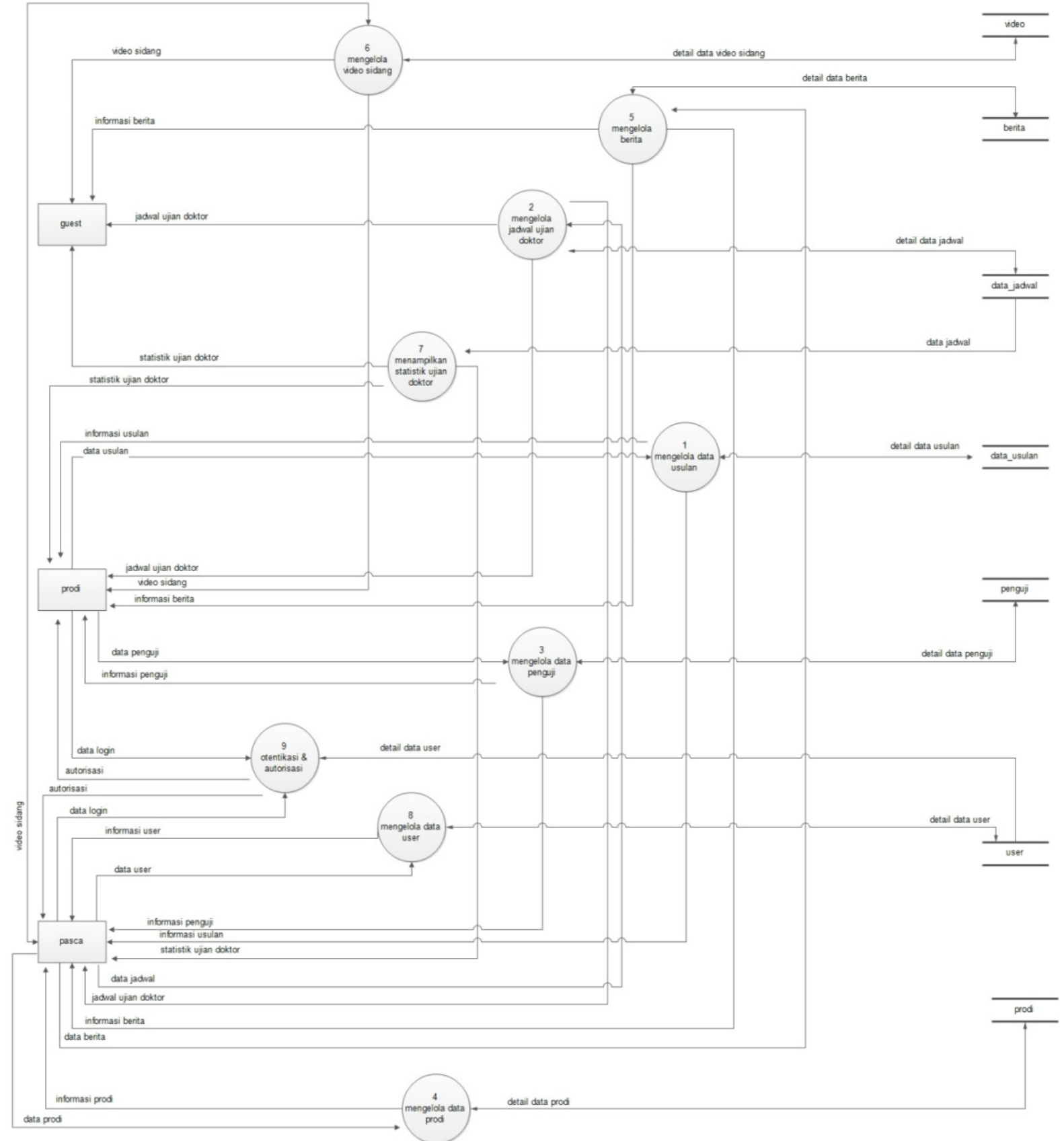

Gambar 4. Data Flow Diagram Level 1 


\section{1) Data Flow Diagram Level 1}

DFD level 1 merupakan penjabaran dari diagram dekomposisi pada level 1. DFD Level 1 memiliki 3 entitas luar yaitu guest, prodi (administrator program studi), dan pasca (administrator pascasarjana) serta memiliki 9 proses.

\section{2) Data Flow Diagram Level 2 Proses 1}

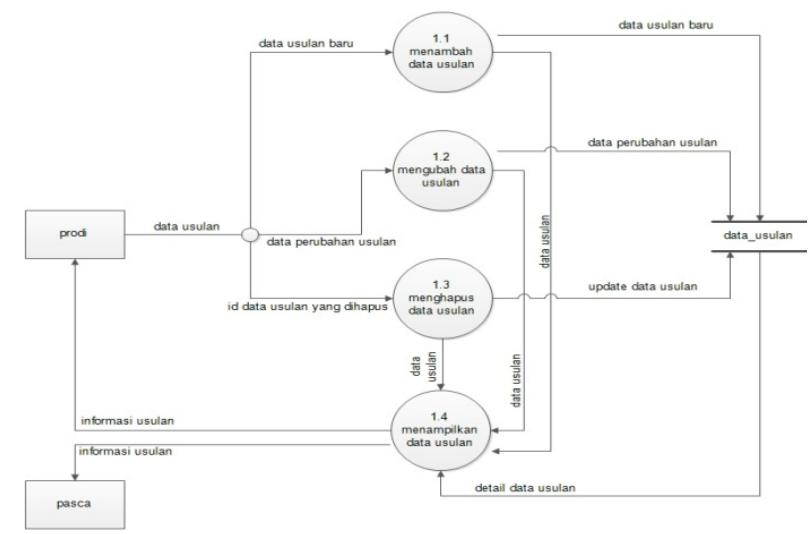

Gambar 5. Data Flow Diagram Level 2 Proses

1 Sistem Penjadwalan Ujian Doktor

DFD Level 2 dari proses 1 merupakan rancangan lebih spesifik dari proses mengelola data usulan. Sub proses yang terdapat di proses 1 antara lain menambah data usulan, mengubah data usulan, menghapus data usulan, dan menampilkan data usulan yang data-data ini akan disimpan pada data store data usulan.

\section{3) Data Flow Diagram Level 2 Proses 2}

DFD Level 2 dari proses 2 merupakan rancangan lebih spesifik dari proses mengelola jadwal ujian doktor. Sub proses yang terdapat di proses 2 antara lain mengecek data usulan apakah sudah ada dan benar atau belum data usulan ini didapat dari data store data usulan, menambah jadwal ujian doktor, mengubah jadwal ujian doktor, menghapus jadwal ujian doktor, dan menampilkan jadwal ujian doktor yang data-data ini akan disimpan pada data store data jadwal.

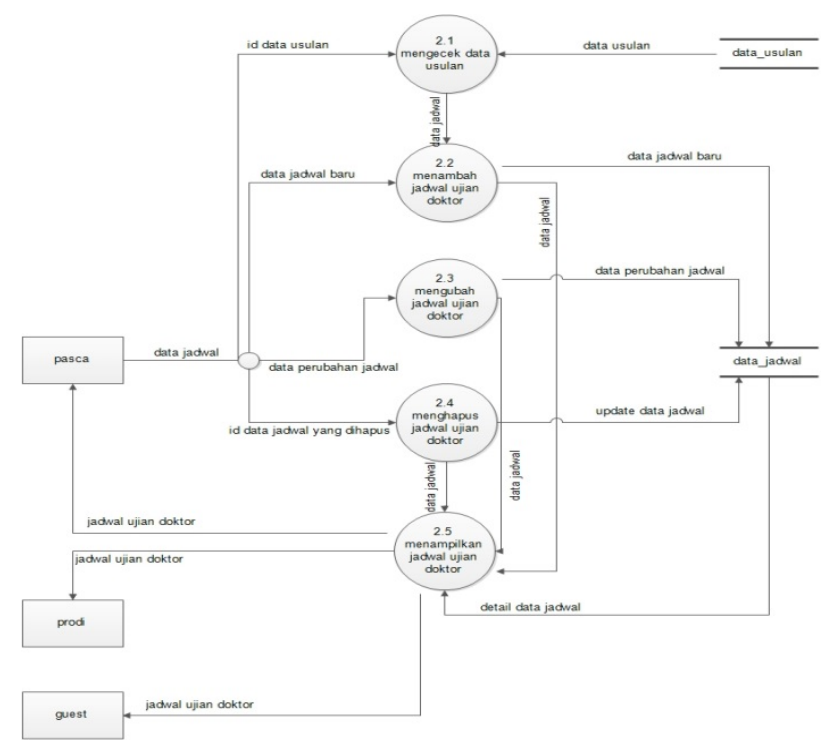

Gambar 6. Data Flow Diagram Level 2 Proses 2 Sistem Penjadwalan Ujian Doktor

4) Data Flow Diagram Level 2 Proses 3

DFD Level 2 dari proses 3 merupakan rancangan lebih spesifik dari proses mengelola data penguji. Sub proses yang terdapat di proses 3 antara lain menambah data penguji, mengubah data penguji, menghapus data penguji, dan menampilkan data penguji yang data-data ini akan disimpan pada data store penguji.

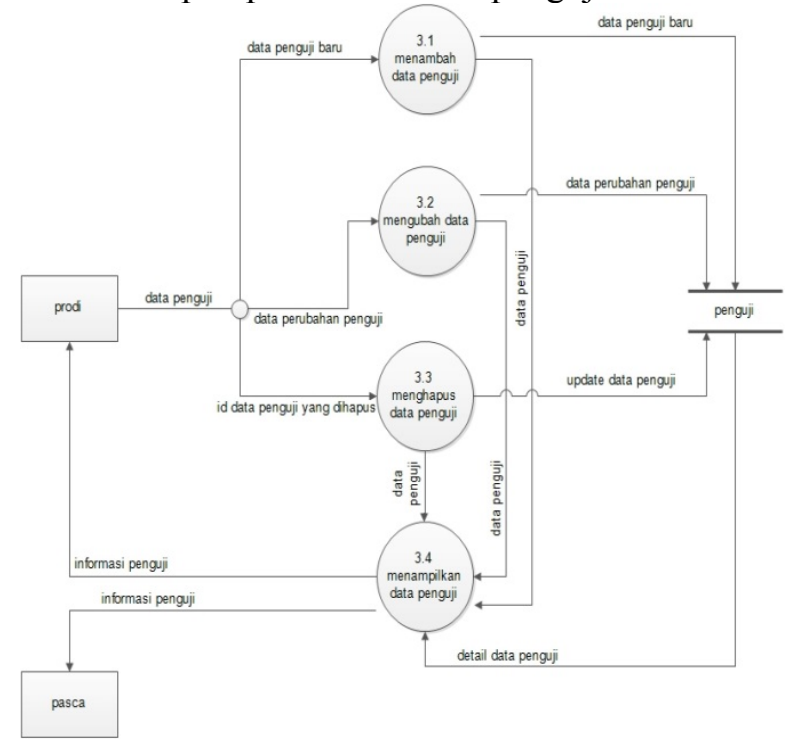

Gambar 7. Data Flow Diagram Level 2 Proses 3 Sistem Penjadwalan Ujian Doktor 
5) Data Flow Diagram Level 2 Proses 4

DFD Level 2 dari proses 4 merupakan rancangan lebih spesifik dari proses mengelola data prodi. Sub proses yang terdapat di proses 4 antara lain menambah data prodi, mengubah data prodi, menghapus data prodi, dan menampilkan data prodi yang data-data ini akan disimpan pada data store prodi.

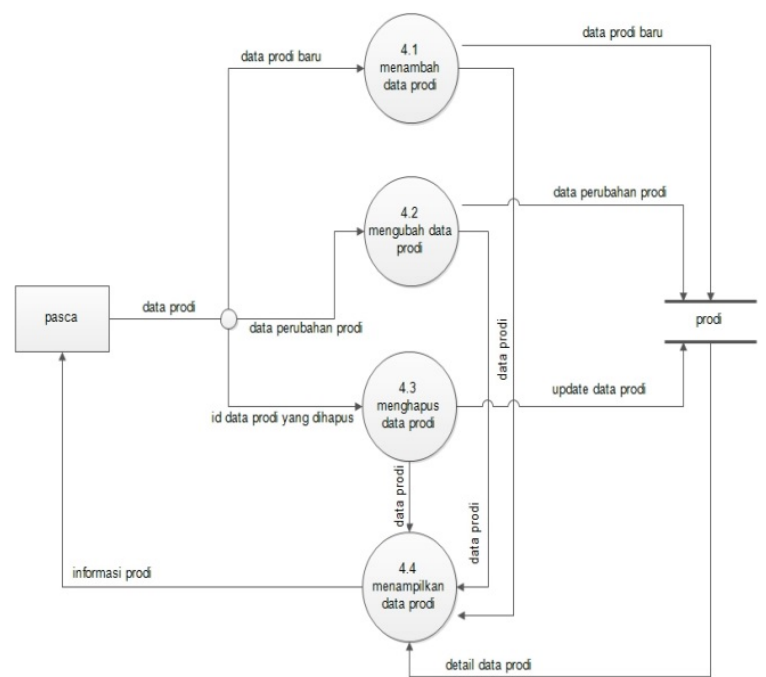

Gambar 8. Data Flow Diagram Level 2 Proses 4 Sistem Penjadwalan Ujian Doktor

6) Data Flow Diagram Level 2 Proses 5

DFD Level 2 dari proses 5 merupakan rancangan lebih spesifik dari proses mengelola berita. Sub proses yang terdapat di proses 5 antara lain menambah berita, mengubah berita, menghapus berita, dan menampilkan berita yang data-data ini akan disimpan pada data store berita. DFD ini ditunjukkan pada gambar 9 .

7) Data Flow Diagram Level 2 Proses 6

DFD Level 2 dari proses 6 merupakan rancangan lebih spesifik dari proses mengelola video sidang. Sub proses yang terdapat di proses 6 antara lain mengupload video sidang, menghapus video sidang, mendownload video sidang, dan menampilkan video sidang yang data-data ini akan disimpan pada data store video. DFD ini dapat dilihat pada gambar 10.
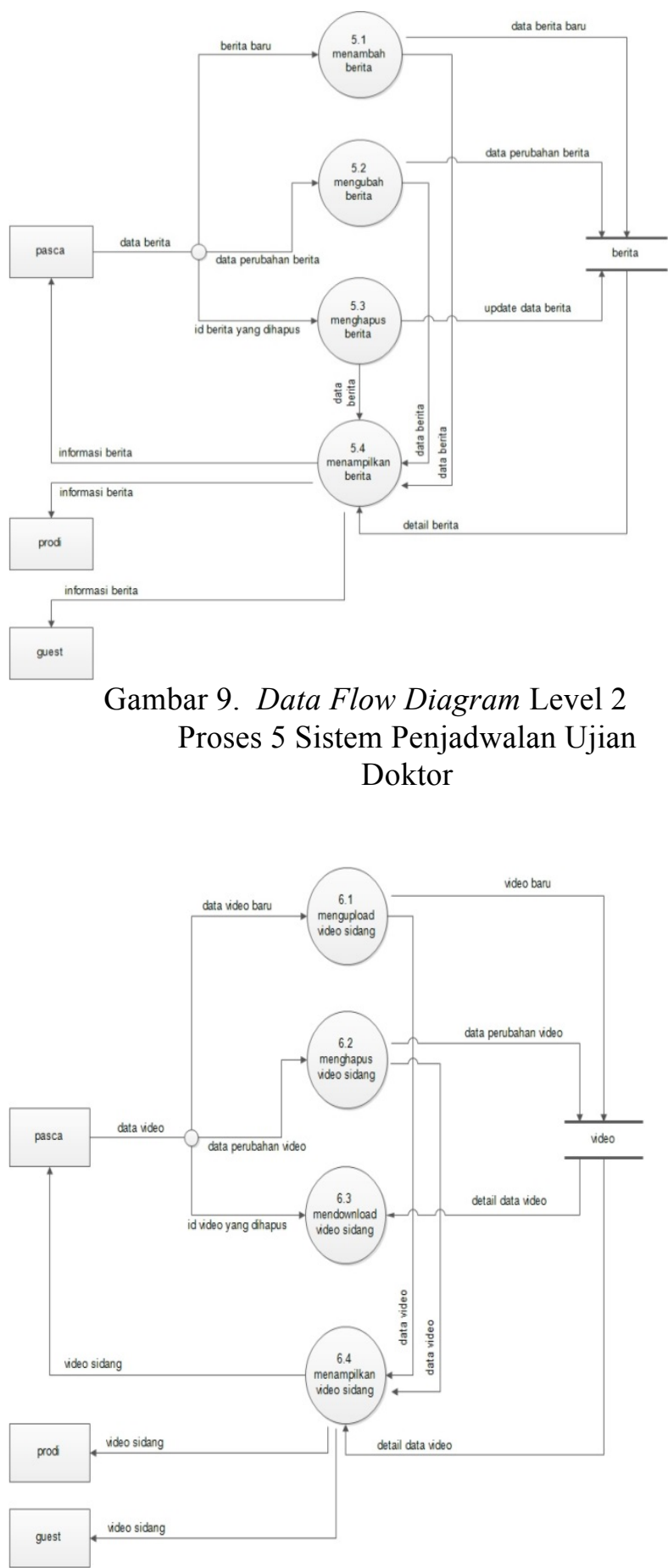

Gambar 10. Data Flow Diagram Level 2 Proses 6 Sistem Penjadwalan Ujian Doktor

8) Data Flow Diagram Level 2 Proses 8

DFD Level 2 dari proses 8 merupakan rancangan lebih spesifik dari proses mengelola data user. Sub proses yang terdapat di proses 8 antara lain menambah data user, mengubah data 
user ,menghapus data user, dan menampilkan data user yang data-data ini akan disimpan pada data store user.

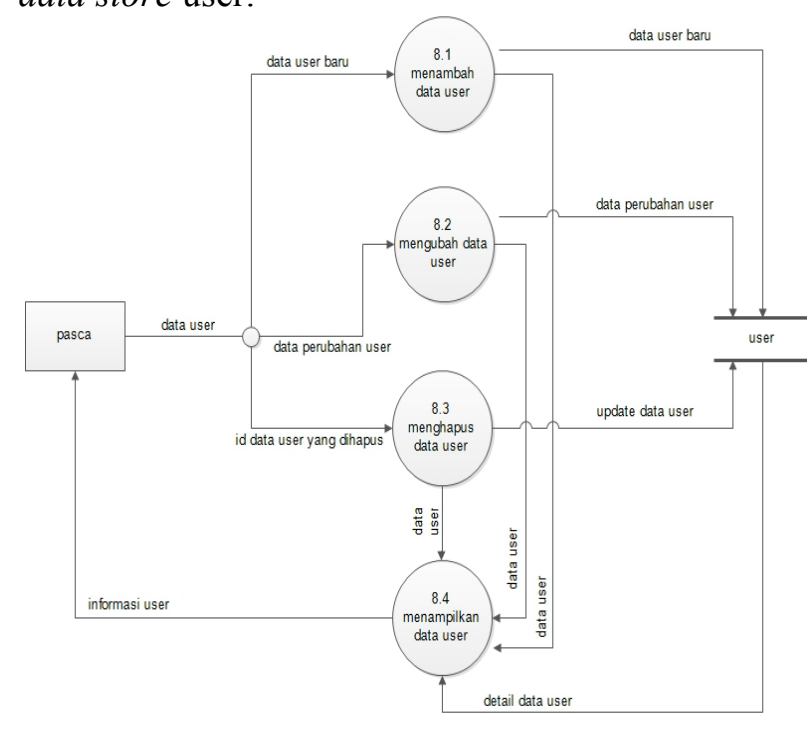

Gambar 11. Data Flow Diagram Level 2 Proses

8 Sistem Penjadwalan Ujian Doktor

\section{IMPLEMENTASI DAN PENGUJIAN}

Implementasi sistem merupakan tahap dimana sistem ini siap dioperasikan pada keadaan sebenarnya. Pembahasan ini akan diketahui apakah sistem yang dibuat benar-benar dapat menghasilkan tujuan yang diinginkan yang didasarkan pada analisis dan design yang telah dilakukan.

Implementasi Sistem Penjadwalan Ujian Doktor dapat dilihat pada gambar 12 sampai dengan gambar 19 berikut ini :

1) Halaman Login dan Home

Saat pertama kali menggunakan sistem, halaman pertama kali yang akan muncul adalah halaman home guest dimana berisi menu yang dapat diakses serta di pojok kiri atas akan terdapat form untuk login baik login untuk administrator program studi maupun administrator pascasarjana. Halaman ini ditunjukkan pada gambar 12 .

2) Halaman Tambah Data Usulan

Pada halaman ini pengguna (administrator program studi) dapat menambahkan data usulan. Data usulan yang ditambahkan hanya dapat ditambahkan satu persatu tidak dapat langsung menambahkan dua atau lebih data usulan sekaligus. Halaman tambah data usulan ditunjukkan pada gamabr 13 .

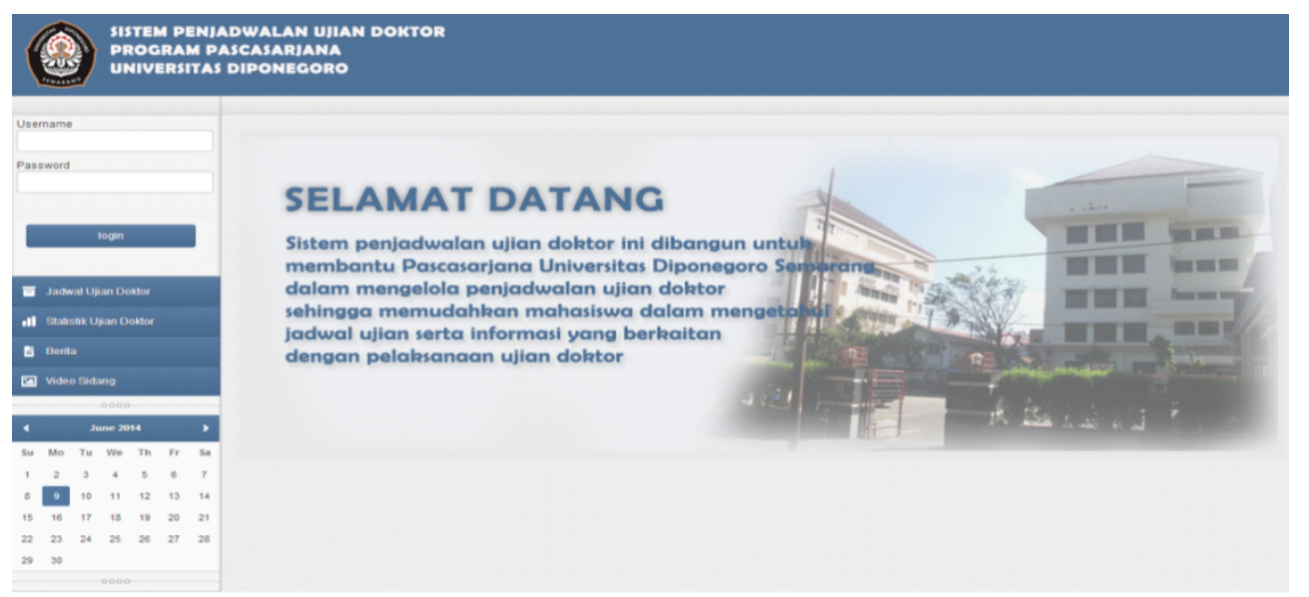

Gambar 12. Halaman Login dan Home 


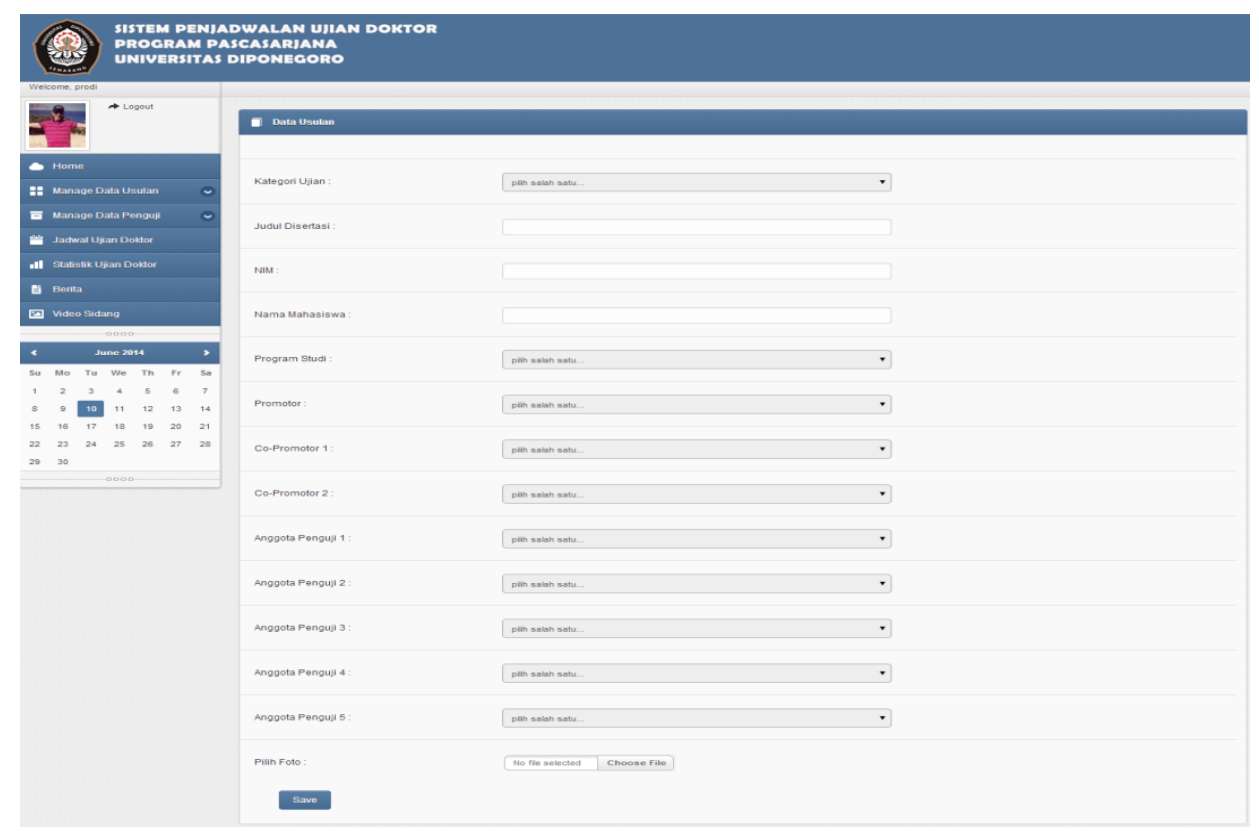

Gambar 13. Halaman Tambah Data Usulan

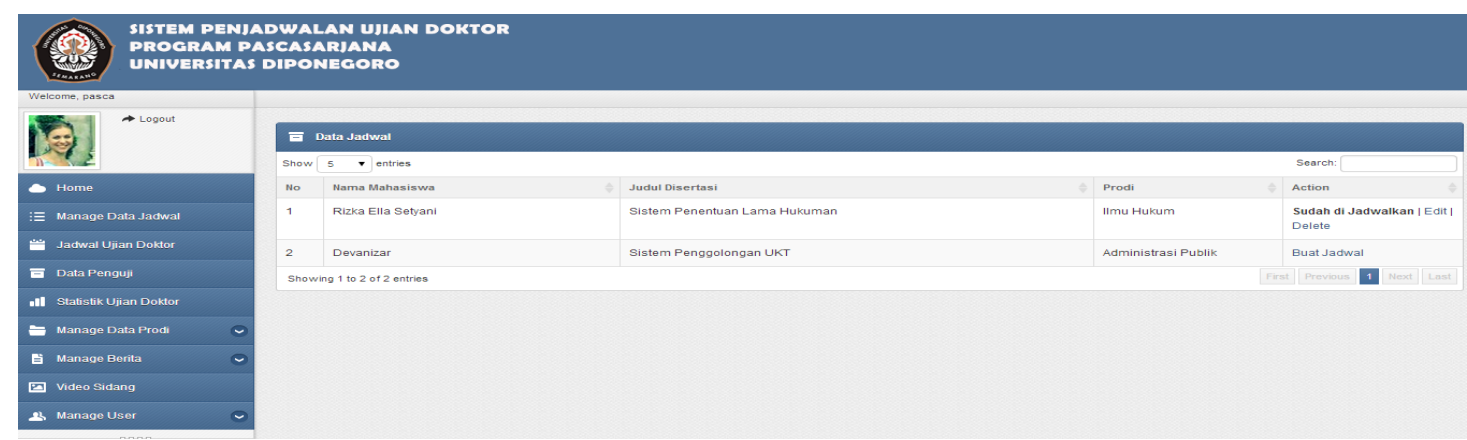

Gambar 14. Halaman Manage Data Jadwal

3) Halaman Manage Data Jadwal

Pada halaman ini pengguna (administrator pascasarjan) dapat melihat semua data usulan yang telah diinput oleh administrator program studi yang disajikan dalam bentuk tabel dimana pengguna dapat memilih tombol buat jadwal.

Halaman Manage data jadwal ditunjukkan pada gambar 14.

\section{4) Halaman Buat Jadwal}

Pada halaman ini pengguna (administrator pascasarjana) dapat menambahkan data jadwal. Data jadwal yang ditambahkan hanya dapat ditambahkan berdasarkan pada data usulan yang sudah ada. Pada saat membuat jadwal ujian sebelumnya akan ditampilkan detail dari data usulan yang akan dibuat jadwal.

Tampilan halaman buat jadwal ini ditunjukkan pada gambar 15 .

\section{5) Halaman Jadwal Ujian Doktor}

Pada halaman ini pengguna dapat melihat jadwal ujian doktor secara sistematis karena ditampilkan perbulan dan apabila pada tanggal yang ditandai di klik akan muncul detail dari pelaksanaan ujian doktor tersebut.

Untuk tampilannya diteunjukkkan pada gambar 16. 
SISTEM PENJADWALAN UJIAN DOKTOR PROGRAM PASCASARJANA
UNIVERSITAS DIPONEGORC
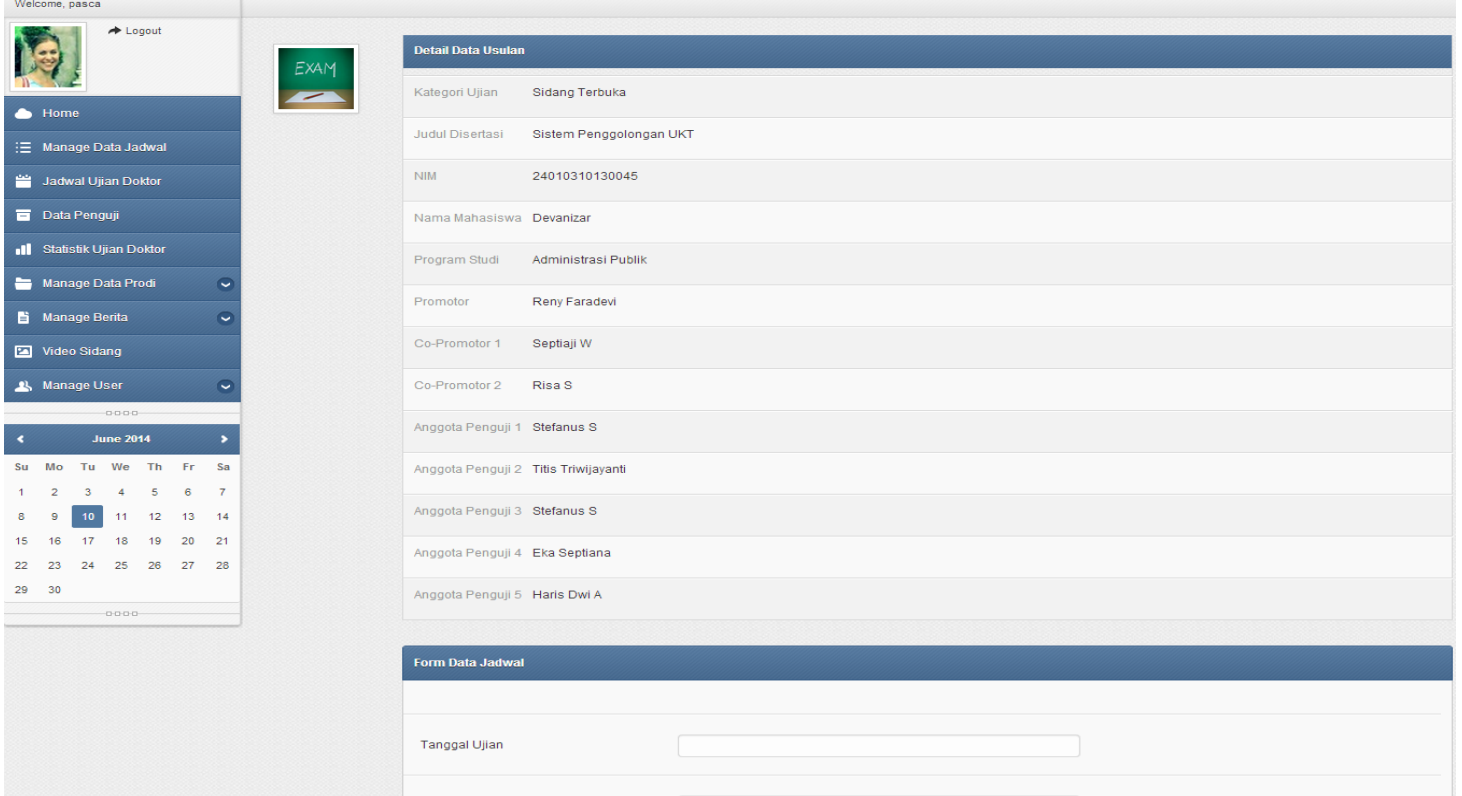

Jam Ujian

Tempat Ujian

Hasil Ujia

Tanggal Ujian Selanjutryy

Gambar 15. Halaman Buat Jadwal
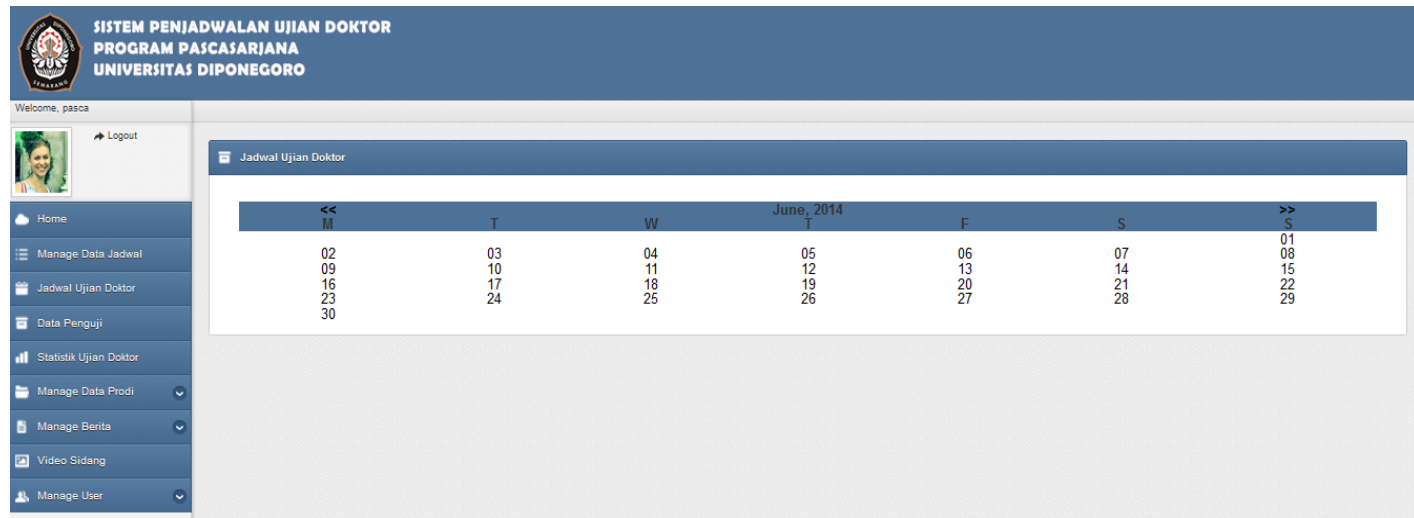

Gambar 16. Halaman Jadwal Ujian Doktor

\section{6) Halaman Statistik Ujian Doktor}

Pada halaman ini pengguna dapat melihat grafik

banyaknya mahasiswa yang melakukan ujian berdasarkan kategori ujiannya

7) Halaman Lihat Berita
Pada halaman ini pengguna dapat melihat berita terkini yang berkaian dengan ujian doktor. Untuk level administrator pascasarjana diberikan menu untuk edit dan delete berita. 8) Halaman Lihat Video Sidang 
Pada halaman ini pengguna dapat melihat data video sidang yang telah diupload yang disajikan dalam bentuk tabel. Untuk guest dan administrator program studi hanya dapat mendownload dan memutar video sidang. Sedangkan untuk administrator pascasarjana dapat mengupload dan menghapus video sidang.

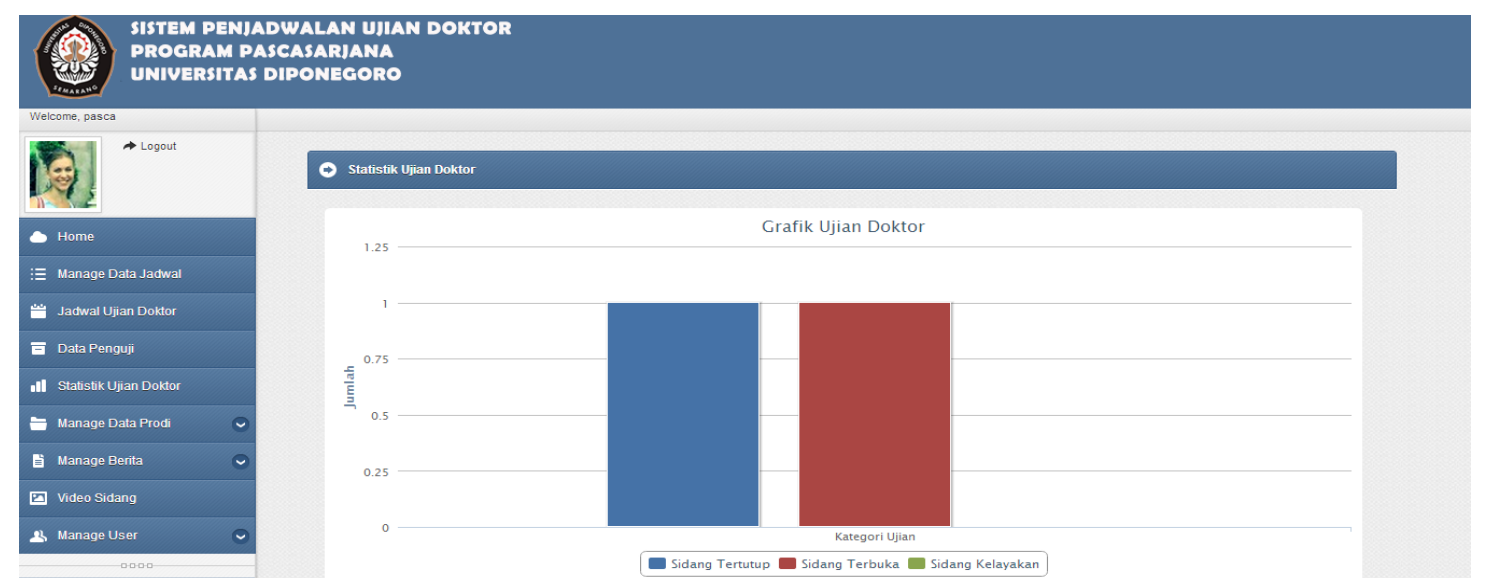

Gambar 17. Halaman Statistik Ujian Doktor

\section{SISTEM PENJADWALAN UJIAN DOKTOR}

PROGRAM PASCASARJANA

UNIVERSITAS DIPONEGORO
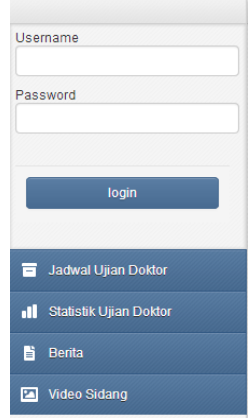

\section{Informasi Terkin}

Lorem Ipsum

Lorem Ipsum is simply dummy text of the printing and typesetting industry. Lorem Ipsum has been the industrys standard dummy text ever since the 1500s, when an unknown printer took a galley of type and scrambled it to make atype specimen book. It has survived not only five centuries, but also the leap into electronic typesetting, remaining essentially ynchanged. It was popularised in the
1960 s with the release of Letraset sheets containing Lorem losum passages, and more recently with des Lorem Ipsum

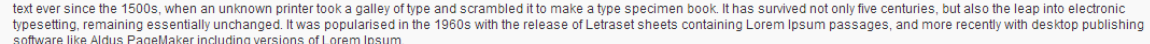

Gambar 18. Halaman Lihat Berita SISTEM PENJADWALAN UJIAN DOKTOR

PROGRAM PASCASARJANA

UNIVERSITAS DIPONEGORO
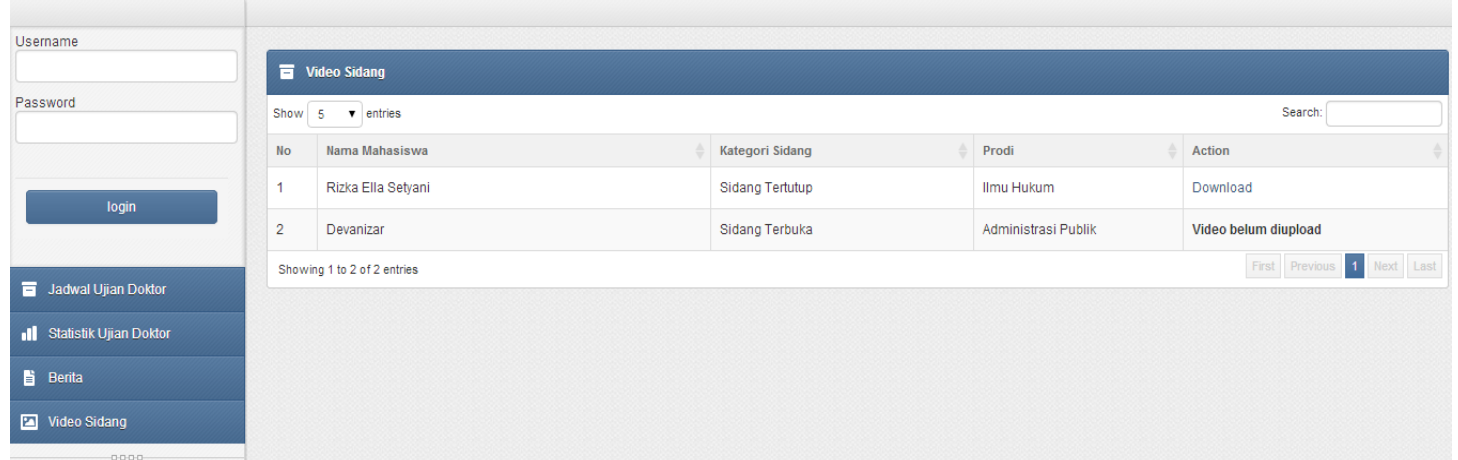

Gambar 19. Halaman Lihat Video Sidang 
Pengujian Sistem Penjadwalan Ujian Doktor menggunakan metode blackbox, yaitu melakukan pengujian fungsionalitas dari perangkat lunak untuk menemukan kesalahan pada persyaratan fungsional dengan mengabaikan mekanisme internal atau komponen dari program tersebut. Pengujian blackbox diterima jika fitur-fitur dari perangkat lunak telah memenuhi kebutuhan aplikasi. Pengujian terhadap sistem ini telah dilakukan dan berhasil, semua fungsi telah berjalan sesuai dengan kebutuhan sistem [1].

\section{KESIMPULAN}

Penelitian pada Pascasarjana Universitas Diponegoro menghasilkan Sistem Penjadwalan Ujian Doktor yang digunakan untuk mengelola semua data yang diperlukan untuk ujian doktor dan berhasil diimplementasikan untuk memudahkan kinerja administrator yang bertugas membuat jadwal dan mengelola data mahasiswa yang akan melakukan ujian doktor agar tidak terjadi jadwal yang bertabrakan sehingga dapat lebih terstruktur, dapat menambah keakuratan data, dan mempercepat pemrosesan data yang ada. Bagi mahasiswa sistem ini mempermudah dalam mengetahui jadwal ujian, statistik ujian doktor, serta informasi yang berkaitan dengan pelaksanaan ujian doktor karena dapat diakses secara online.

Saran-saran yang dapat dilaksanakan untuk pengembangan Sistem Penjadwalan
Ujian Doktor lebih lanjut adalah sebagai berikut :

a) Penambahan fungsi untuk melihat statistik ujian doktor dalam tiap bulannya.

b) Sistem Penjadwalan Ujian Doktor dapat dikembangkan lagi menjadi sebuah sistem yang lebih baik lagi dari sebelumnya, dengan tambahan fitur lain yang dapat menunjang kemudahan seperti untuk melakukan backup dan restore basis data.

\section{DAFTAR PUSTAKA}

[1] Pahinsa, Renegard. 2010. "Definisi Pengujian Perangkat Lunak (PL)", (Online), (http://renegardpahinsa.blogspot.com/ 2010/05/definisi-pengujian-perangkatlunakpl.html, diakses pada 02 Juni 2014).

[2] Peranginangin, K. 2006. Aplikasi Web dengan PHP dan MySQL. Yogyakarta: Penerbit Andi.

[3] Pressman, R. S. 2001. Software Engineering : A Practitioner's Approach Fifth Edition. New York : McGraw - Hill Companies, Inc.

[4] Rahman, Ricky. 2012. "Permodelan Fungsional dan Aliran Informasi", (Online), (http://rickyrahmanharvard.blogspot.c om/2012/06/pemodelan-fungsionaldanaliran.html, diakses pada 21 Mei 2014). 